\title{
Methodologies for an improved prediction of the isotopic content in high burnup samples. Application to Vandellós-II reactor core
}

\author{
J.S. Martínez , O. Cabellos, C.J. Díez
}

\begin{abstract}
A B S T R A C T
Fuel cycles are designed with the aim of obtaining the highest amount of energy possible. Since higher burnup values are reached, it is necessary to improve our disposal designs, traditionally based on the conservative assumption that they contain fresh fuel. The criticality calculations involved must consider burnup by making the most of the experimental and computational capabilities developed, respectively, to measure and predict the isotopic content of the spent nuclear fuel. These high burnup scenarios encourage a review of the computational tools to find out possible weaknesses in the nuclear data libraries, in the methodologies applied and their applicability range. Experimental measurements of the spent nuclear fuel provide the perfect framework to benchmark the most well-known and established codes, both in the industry and academic research activity.

For the present paper, SCALE 6.0/TRITON and MONTEBURNS 2.0 have been chosen to follow the isotopic content of four samples irradiated in the Spanish Vandellós-II pressurized water reactor up to burnup values ranging from $40 \mathrm{GWd} / \mathrm{MTU}$ to $75 \mathrm{GWd} / \mathrm{MTU}$. By comparison with the experimental data reported for these samples, we can probe the applicability of these codes to deal with high burnup problems. We have developed new computational tools within MONTENBURNS 2.0. They make possible to handle an irradiation history that includes geometrical and positional changes of the samples within the reactor core. This paper describes the irradiation scenario against which the mentioned codes and our capabilities are to be benchmarked.
\end{abstract}

\section{Introduction}

Nuclear fuel exploitation for energy production generates actinides and fission products. Their properties make the spent nuclear fuel a waste difficult to handle without any shadow of controversial. For this reason, security and safety become key words for any storage or reprocessing strategy. Criticality value is an essential parameter to control and guarantee their safety, not only during the fuel irradiation but also afterwards, during its transportation and storage. Storage containers fulfil criticality safety requirements by considering that their content is an array of fresh nuclear fuel. The improvement of the spent fuel characterization, both experimental and predictive by simulation, can benefit the post-irradiation strategies. For example, burnup credit could lead to the design of alternative transport and storage casks more compact, economical and capable of storing a higher number of spent assemblies without renouncing safety. Burnup credit is important in this sense because the prospect for the nuclear fuel exploitation is to increase the final burnup level, due to the future possibility of exploitation in advanced subcritical reactors and due to the nonproliferation spirit that should pervade any nuclear programme.

To achieve a reliable knowledge of the final burnup means to guarantee the agreement between its experimental final composition and the theoretical composition that can be expected according to its irradiation history. To put it in other words, the measured values must meet the predicted ones. In recent years, it has been done a meaningful effort to develop computing tools and complex codes that follow the isotopic evolution throughout depletion. The solution of the Bateman equations can be considered as first approach, but it is unrealistic; an accurate monitoring of the depletion has to consider not only compositional variations but also changes in the system neutronics and cross-sections. The most realistic choice to handle this problem is to couple neutron transport and depletion calculations in a cyclic fashion. SCALE 6.0/TRITON (DeHart, 2009) module and MONTEBURNS 2.0 (Poston and Trellue, 1999) are only two examples of coupling codes.

Both are used for the purpose of the present paper: to predict the isotopic content measured for increasing burnup samples that were irradiated in Vandellós-II Spanish pressurized water reactor. The main characteristic of our case is the changing position of the sample of interest, what demands to follow its isotopic content trough a changing geometry. An external module, LINK, is designed 
to automate the procedure and manage all the information related to the isotopic content from one cycle to the following one, allowing a flexible and reliable tracking of the compositions. For the present study, MONTEBURNS 2.0 is updated with new capabilities. They are focused on an improved reproduction of the physical irradiation conditions, especially of the power at which the samples were burnt according to the experimental measures. We study the effect of our improvements by analyzing the simulation results for several burnups. The outline of this work is as follows: in Section 2 it is described the irradiation history that applies to the samples whose final content is to be simulated; Section 3 is devoted to a brief review of the codes used; Section 4 summarizes the main methodological improvements implemented in MONTEBURNS 2.0; results from calculations performed with SCALE 6.0, the original MONTEBURNS 2.0 and our updated version are presented and discussed in Section 5 and, finally, some conclusions close this isotopic prediction exercise.

\section{Vandellós-II reactor cycles 7th-11th}

The Spanish pressurized water reactor Vandellós-II was chosen to host test samples in the framework of a deep study about nuclear fuel highly burned up. The experimental characterization of their content can be used to probe the quality of the available depletion codes.

The operation time identified as 7th-11th cycles corresponds to the reactor operation time that ranges from June 1994 and September 2000 . At the beginning of the 7 th cycle, fresh fuel rods enriched up to 4.5 wt.\% U-235 were placed at different locations within the reactor core. The assemblies that hosted them changed from one cycle to the following and, finally, for the duration of the 11th cycle, rods of interest became part of an assembly placed near the center. This last host assembly had an initial enrichment of 4.24 wt.\% U-235 and a burnup of 26.5 GWd/MTU. After their extraction and cooling, the isotopic content of these test rods was measured by different techniques in two campaigns that took place at the Studsvik laboratories in 2003 and 2006. We refer our calculations only to the test rod labeled as WZR0058 (Zwicky et al., 2010).

\subsection{Samples specifications and main characteristics of the irradiation history}

Rod WZR0058 started its irradiation with an enrichment of 4.5 wt.\% U-235. Its position at the outmost part of the host assembly, enriched up to the same value, remained unchanged from the 7 th to the 10 th cycle, while the assembly itself moved from the periphery of the core ( 7 th and 8th cycles) to the center (9th cycle) and from the center to the periphery again, facing this time the water reflector (during 10th cycle). Finally, the rod of interest was removed from the original assembly and inserted into a new one near the center of the reactor core (11th cycle). As a result of all these displacements, rod WZR0058 burnup was influenced by different neighboring conditions that (together with the irradiation and decay history and other physical parameters implied, like boron letdown curves, densities and temperatures, etc.) (Ilas and Gauld, 2009) determined its final average value. The Fig. 1 summarizes graphically the changes explained above.

These five irradiation periods alternated with decay periods as shown in Table 1.

At the end of its burnup, WZR0058 was extracted and several samples were cut out from different axial positions in order to obtain their isotopic composition experimentally. As a result from an adequate treatment of the data, it is possible to provide a set of nuclide concentrations for each sample. Their final compositions are

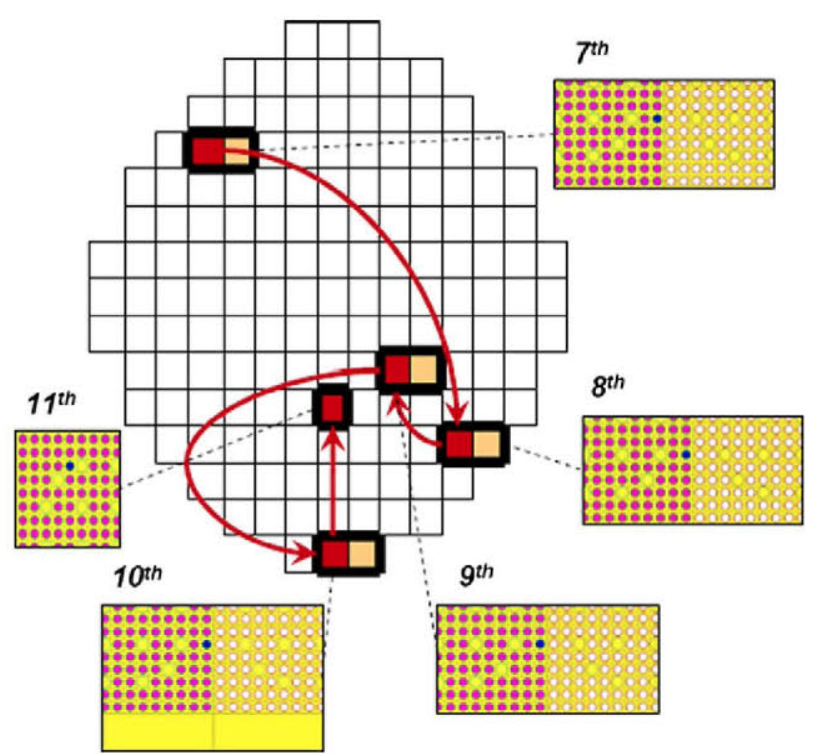

Fig. 1. Changes of the host assembly within the reactor core and relative position of WZR0058 from 7 th to 11 th cycle.

Table 1

Duration of the irradiation and decay periods.

\begin{tabular}{lll}
\hline Cycle & Irradiation (days) & Decay (days) \\
\hline 7 th & 358 & 33 \\
8 th & 330 & 35 \\
9 th & 407 & 31 \\
10 th & 535 & 50 \\
11 th & 496 & - \\
\hline
\end{tabular}

Table 2

Estimated burnups based on burnup indicators.

\begin{tabular}{ll}
\hline Sample ID & Sample burnup (GWd/MTU) \\
\hline E58-88 & 42.489 \\
E58-148 & 54.820 \\
E58-260 & 64.624 \\
E58-700 & 77.013 \\
\hline
\end{tabular}

different because of the different final burnup reached by each sample, consequence of the different power level at which they were irradiated at their corresponding axial positions. Table 2 lists the burnups of the samples whose content was reported. Samples are labeled according to the common label "E58-" and their axial position measured in millimeters from the bottom of the core. These burnup values correspond to an adjustment of the theoretical ones (based on operational data) to the Nd-148 and Cs-137 content in each sample (Ilas and Gauld, 2009).

The irradiation history that leads to these burnup values can be modeled. Needless to say, apart from the power levels, boron letdown curves and coolant density and temperature profiles have to be considered for an accurate simulation of the irradiation of each axial node (Gauld et al., 2010) (Chabert and Santamarina, 2000).

\subsection{Simulation model characteristics}

The idea of this work is to reproduce the isotopic content for the burnups listed in Table 2, that is, for the four representative samples E58 extracted from increasing axial positions of WZR0058. 
Four simulations have to be performed in order to obtain the calculated set of isotopes that we compare to the corresponding experimental data. As Fig. 1 suggests, each simulation consists on five steps (one by cycle) due to the geometrical and material changes explained in the previous sections. It is clear from Fig. 1 that tenth and eleventh cycle have to be modeled separately: tenth cycle includes a portion of water reflector not present before and eleventh cycle allocates rod WZR0058 nearer the center of the assembly. On the other hand, although cycles seventh, eighth and ninth maintain the WZR0058 position and surrounding geometrical configuration, the material composition of the neighbor assembly changes from cycle to cycle, merely because they are different assemblies. Moreover, the neighbor assemblies are not necessarily fresh, so their content at the beginning of each cycle must be previously calculated. All these considerations justify the number of simulation steps to perform: five for each cycle and four for the previous burnups of the neighbor assemblies. This procedure applies to each representative sample: they share the simulation flow because they belong to the same rod. However, each of the four irradiation histories have to be modeled independently due to the different power levels, moderator density and boron letdown curves that affect their burnup (Ilas and Gauld, 2009). It is inescapable the complexity of the simulation. We highlight that one of the most important points to face is the correct management of the information between simulation steps.

\section{Used codes. Main implementations}

SCALE 6.0, developed at the Oak Ridge National Laboratory, has become in recent years a code widely used for calculations involving nuclear reactor physics, such as criticality and depletion calculations. One of the modules included in the SCALE 6.0 code package is TRITON, which makes easy the study of the isotopic evolution of fuel under irradiation by the coupling of the 2-D deterministic transport code NEWT and the depletion and decay code ORIGEN$S$; the former solves the transport problem and provides the latter with cross-sections and averaged neutron fluxes that it uses in the subsequent depletion calculation, the result of which updates the isotopic content and material composition for the next NEWT calculation. This iterative way to perform the fuel depletion guarantees a realistic monitoring of the isotopic evolution. Another two interesting capabilities of TRITON for the present problem are:

- The power normalization: user can specify the power at which a material burns and normalize the rest of the material fluxes according to this requirement. This makes possible to reproduce experimental burnups.

- The isotopic files: once finished the calculation, TRITON prints the isotopic content of the materials selected by the user and it is possible to use them as inputs for another case or geometry. Thanks to this capability, we can follow the isotopic content of the samples throughout the entire irradiation taking into account the changing surroundings. The isotopic files printed by TRITON for each material include all the isotopes deemed important for transport calculations, that is, for NEWT calculations. This implies a lack of information because there is a huge amount of isotopes tracked by ORIGEN-S in the decay calculations that is not included in this isotopic file. The lack of these nuclides does not benefit the isotopic prediction calculation.

MONTEBURNS 2.0, developed at Los Alamos National Laboratory, is a coupling code written to automate the process of providing ORIGEN2 with one-group microscopic cross-sections and neutron fluxes from MCNP transport calculations, and providing
MCNP with updated material compositions from ORIGEN2 decay calculations. Similarly to TRITON, the calculation strategy followed is iterative throughout the modeled burnup history. The approximation assumed by MONTEBURNS 2.0 is the middle-of-step constant flux approximation. MONTEBURNS 2.0 broadens its coupling capability by offering the possibility of using CINDER90 as depletion module. The geometrical versatility of MCNP allows us to model the problem introduced above. The options of MONTEBURNS 2.0 allow us to reproduce the physical conditions at which the samples burn. Nevertheless, when compared to SCALE 6.0, we find two issues to think about:

- MONTEBURNS 2.0 uses a power value referred to the entire modeled system. It is not possible to burn the sample of interest at a power value without distorting the power of the rest of the assembly.

- Once defined the MCNP geometry, it is maintained till the end of the calculation. This makes mandatory to write several inputs if it is desired a simulation of the position and geometrical changes.

These two questions aimed to develop some new tools for MONTEBURNS 2.0 and an external code, LINK, to coordinate the consecutive executions without lack of information.

\subsection{Capabilities implemented in MONTEBURNS 2.0}

The two issues pointed out above aim to the modification of the original code MONTEBURNS 2.0 and the development of an external tool to solve automatically the Vandellós-II problem.

\subsubsection{LINK: isotopic management for transport and decay calculations}

As explained before, reproducing the geometries of each cycle obliges us to model them separately and, then, to execute them with MONTEBURNS 2.0 one by one, a task that has to be carried out not only for the nominal cycles ( 7 th-11th) but also for the possible previous cycles of the neighbor assemblies. That means to take the resulting compositions at the end of each simulation and to update the initial compositions of the following one by hand. Fig. 2 illustrates the scheme of the simulations to perform.

This process implies a lot of time and the possibility of making mistakes. Our external code, LINK:

- Automates a serial of executions.

- Carries out automatically the material managing between the inputs, that is, takes final compositions and writes them as part of the initial composition of the desired geometrical models.

- Manages the entire inventory: the isotopes considered for the MCNP transport calculations and the isotopes decayed by ORIGEN. It writes specific files to be read by ORIGEN as input files at the beginning of the burnup step. LINK does not allow any lack of information in the updating process.

Fig. 3 is a simplified version of the complete LINK flow chart, which involves subroutines added to MONTEBURNS 2.0. However, it shows the scheme that allows us to handle simulations characterized by non-static geometries.

\subsubsection{Power normalization methodology}

In MONTEBURNS 2.0, for each material, MCNP calculates fluxes normalized to one fission source-neutron; to convert these flux values into neutrons per second and $\mathrm{cm}^{2}$, MONTEBURNS $2.0 \mathrm{mul}-$ tiplies by the constant factor recommended in the MCNP manual (X-5 Monte Carlo Team, 2003). 


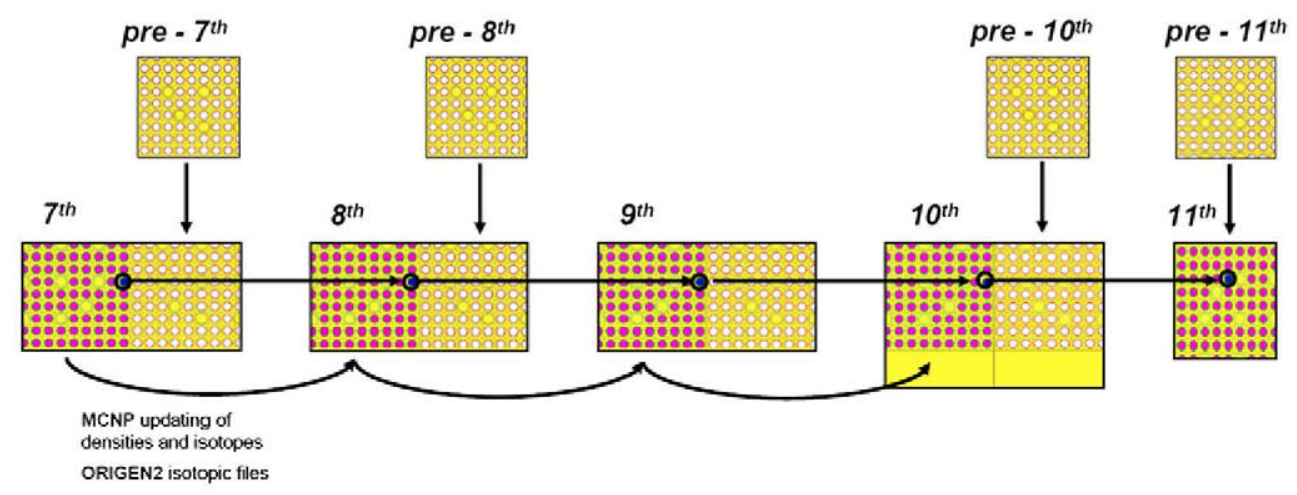

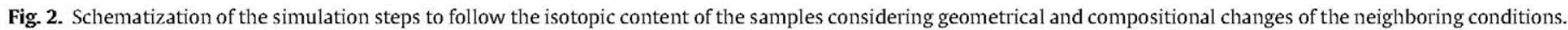

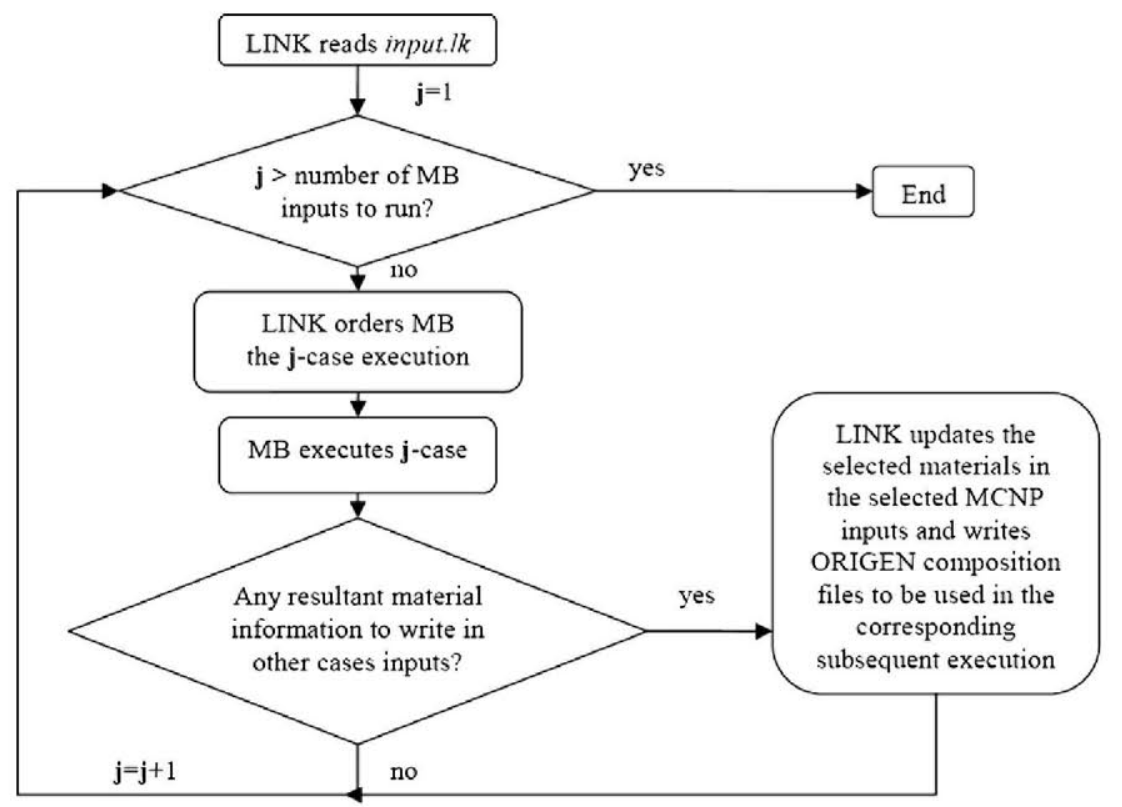

Fig. 3. LINK. Conceptual flow chart.

$C=\frac{v}{k_{\text {eff }}} \frac{P}{Q_{\text {ave }}} \frac{10^{6} \mathrm{~W} / \mathrm{MW}}{1.602 \times 10^{-13} \mathrm{~J} / \mathrm{MeV}}$

where $P(\mathrm{MW})$ is the total power of the entire system modeled in MCNP and entered as input in MONTEBURNS, $v$ is the average number of fission neutrons per fission event, $Q_{a v e}$ is the average recoverable energy per fission event ( $/ /$ fission) and $k_{\text {eff }}$, the eigenvalue of the system. All the materials are, then, equally normalized and MONTEBURNS assigns to each one a power value depending on the volume they occupy, their macroscopic fission cross-section and their neutron flux level. This treatment cannot guarantee the depletion of a pin-cell at the experimental power suggested by burnup indicators when it is modeled as part of a fuel assembly. The factor

$$
C^{*}=\frac{P_{\text {norm }}}{\sum_{j=n}^{m}\left\{\sum_{f}^{j} \varphi_{j} V_{j} Q_{j}\right\}} \frac{10^{6} \mathrm{~W} / \mathrm{MW}}{1.602 \times 10^{-13} \mathrm{~J} / \mathrm{MeV}}
$$

where $P_{\text {norm }}$ is the corresponding total power of all the materials selected as basis of normalization, $j[n, m]$ the one of the materials, $j$ part of the basis normalization, made of all the materials from $n$ to $m, \sum_{f}^{j}$ the fission macroscopic cross-section for material $j, \varphi_{j}$ the unnormalized neutron flux in material $j$ tallied by MCNP, $V_{j}$ the volume occupied by material $j$ and $Q_{j}$ is the average recoverable energy per fission event in material $j$ allows the user to select one or more materials as basis of normalization, to introduce in MONTEBURNS the corresponding power and to normalize the rest of the materials to the selected flux levels. Thus, each material, $i$, is depleted at a power given by

$P^{i}=\frac{P_{\text {norm }}}{\sum_{j=n}^{m}\left\{\sum_{f}^{j} \varphi_{j} V_{j} Q_{j}\right\}} Q^{i} \sum_{i}^{f} V^{i} \varphi^{i}$

what makes possible to burn the material of interest at the desired power value. It must be noted the importance of this implementation if the user is interested in an isotopic prediction adjusted to the estimated burnup of a specific sample. When measured, the composition of a sample gives us an idea of the burnup finally reached and, from this point, a correction of its reported irradiation history is easy to obtain. Nevertheless, the corrected power values are referred only to the sample the burnup of which is simulated. To put it in other words, the user ends up only with information about the irradiation history of the sample and knows nothing about the entire power of the system modeled, which is the value accepted as input by the original MONTEBURNS 2.0. Our implementations allow the user to input the exact power values that apply to the samples of interest, gaining accuracy in the normalization of the fluxes 
within the selected regions and, furthermore, normalizing the rest of the assembly consistently.

\subsubsection{Temperature distribution function}

In MONTEBURNS 2.0 all the materials evolve at the temperature at which the selected library was generated and specified in the MCNP material card. However, when burning different materials at different temperatures, we found that the original MONTEBURNS 2.0 does not respect the temperature distribution desired by the user during the simulation. This way, the burnup model does not reproduce the temperature gradient (fuel, gap, clad, moderator and other structures) of the system. Our MONTEBURNS 2.0 version fixes up this problem by including an external module that recognizes the temperature pattern described in the input and maintains it throughout the simulation. In our case, two continuous-energy ACE format data libraries generated using NJOY99.259 with 0.01 fractional reconstruction tolerance were used, on the one hand, based on ENDF/B-VII.O evaluation (Chadwick et al., 2006). The prepared libraries include a total of 432 nuclides at 6 temperatures, but given the temperature conditions of our problem, only isotopes at $600 \mathrm{~K}$ and $900 \mathrm{~K}$, for moderator and fuel respectively, were necessary.

\section{Results}

To validate our methodologies, cycles $7-11$ modelization series were executed with TRITON and our updated version of MONTEBURNS 2.0. TRITON calculations were performed with the SCALE 44 group cross-section library based on ENDF/B-V data and following the two dimensional depletion sequence, calling NEWT as transport code, ORIGEN-S as depletion code and NITAWL as cross-section processor. MONTEBURNS 2.0 included the option of selecting the libraries generated at different temperatures and was executed by LINK $^{1}$, emulating TRITON execution flow. For MONTEBURNS 2.0 executions, processed libraries at $600 \mathrm{~K}$ and $900 \mathrm{~K}$ based on ENDF/B-VII.0 were chosen. PWRU ORIGEN library was used.

The Vandellós-II problem served us to probe, firstly, the impact of each of the capabilities presented above on the isotopic content calculation and secondly, how much the prediction is affected by them with burnup. We devote the next three sections to describe the executions that were performed, the results we obtained and the conclusions they suggest.

\subsection{Effect of the implemented capabilities on isotopic prediction. Lowest burnup case}

The most important features of our system LINK/[MONTEBURNS $2.0]^{*}$ are the selection of mixtures as basis of power normalization and the automatic management of isotopic contents for MCNP and ORIGEN 2.1 inputs. To analyze the impact of these two improvements, several executions have been carried out for the sample that reached the lowest burnup, that is, E58-88, burnt up to $42.5 \mathrm{GWd}$ / MTU. Specifically, the results are referred to:

- An execution with the normalization methodology and ORIGEN 2.1 isotopic management deactivated: [42.5].

- An execution with ONLY the isotopic management activated: $[42.5]^{i}$.

- An execution with ONLY the normalization capability, with the sample of interest selected as basis of normalization, activated: $[42.5]^{n}$.

- An execution with BOTH capabilities activated: $[42.5]^{n, i}$.
An execution of the problem with SCALE 6.0, as explained before, was performed in order to have an external reference for our calculations. Table 3 shows the deviation of each execution from experimental measures at 1101 days of cooling. The nuclide set selected for comparison is established by the available experimental data (Table 9).

From an inspection of Table 3 , it is possible to establish three categories of isotopes. The first group includes those isotopes for which the prediction is improved by the activation of the normalization methodology. Examples of this family are U-234, U-235, $\mathrm{Pu}-239, \mathrm{Pu}-242, \mathrm{Am}-241$, neodymium (but Nd-142), Cs-133, Ce140 , Ce-142 and Sm-151. Since the sample burns under a more realistic flux level, it is reasonable the improvement in U-235 and $\mathrm{Pu}-239$ prediction, and the corresponding effect on some fission products. The second group is defined by those isotopes for which the prediction improves because of the activation of the ORIGEN 2.1 isotopic management. Few of them have been found: $\mathrm{Pu}-239$, Am-243, Cm-244, Nd-142, Nd-143, Sm-150, Sm-151, Eu154, Eu-155, Gd-156 and La-139. Finally, there are isotopes for which the prediction improves when both capabilities are activated: U-235, Pu-238, Pu-241, Pu-242, neodymium, caesium, cerium (but Ce-144) and europium (but Eu-153). Rare are the isotopes for which none of the capabilities improve the prediction

Table 3

Comparison $(\mathrm{C} / \mathrm{E}-1)^{\text {tays }}$ from discharge with different capabilities activated.

\begin{tabular}{|c|c|c|c|c|c|}
\hline Isos.id & {$[42.5]^{n, i}$} & {$[42,5]^{i}$} & {$[42.5]^{n}$} & [42.5] & SCALE 6.0 \\
\hline $\mathrm{U}-234$ & 8.04 & 8.04 & 5.16 & 7.32 & 4.09 \\
\hline U-235 & 0.58 & 3.64 & 0.85 & 1.64 & -4.03 \\
\hline U-236 & 7.39 & 6.46 & 7.39 & 6.77 & 8.94 \\
\hline Pu-238 & -8.10 & -11.85 & -9.97 & -10.60 & 0.60 \\
\hline Pu-239 & -3.50 & -2.13 & -3.50 & -5.13 & 1.39 \\
\hline Pu-240 & 2.72 & 4.85 & 5.55 & 0.59 & 8.56 \\
\hline Pu-241 & -1.92 & -6.50 & -4.97 & -3.57 & -0.45 \\
\hline Pu-242 & 0.64 & -3.34 & -0.89 & -3.03 & 9.09 \\
\hline $\mathrm{Np}-237$ & -7.37 & -11.87 & -7.90 & -6.58 & -1.54 \\
\hline Am-241 & 21.50 & 20.14 & 18.78 & 21.50 & 24.29 \\
\hline Am-243 & 36.24 & 22.09 & 36.61 & 30.47 & 51.41 \\
\hline $\mathrm{Cm}-244$ & 76.86 & 62.05 & 87.05 & 76.86 & 107.97 \\
\hline $\mathrm{Cm}-246$ & 46.36 & 30.09 & 22.44 & 11.92 & -9.65 \\
\hline Nd-142 & 28.49 & 22.37 & -66.50 & -67.19 & 25.64 \\
\hline Nd-143 & -3.10 & -3.87 & -3.87 & -4.64 & -0.67 \\
\hline Nd-145 & -2.81 & -3.57 & -3.00 & -3.38 & 1.42 \\
\hline Nd-146 & -0.12 & -2.52 & -0.49 & -1.97 & 2.61 \\
\hline Nd-148 & -1.30 & -3.05 & -1.30 & -2.35 & 0.60 \\
\hline Nd-150 & -3.38 & -5.56 & -3.38 & -4.83 & -0.10 \\
\hline Cs-133 & -1.47 & -2.51 & -1.36 & -2.51 & 3.33 \\
\hline Cs-134 & -20.98 & -26.48 & -23.01 & -23.88 & -72.72 \\
\hline Cs-135 & -14.31 & -15.90 & -14.71 & -16.49 & -10.62 \\
\hline Cs -137 & -9.72 & -11.38 & -9.72 & -10.94 & -11.39 \\
\hline Ce-140 & -2.71 & -4.27 & -3.34 & -4.38 & 2.09 \\
\hline $\mathrm{Ce}-142$ & -2.44 & -4.02 & -2.44 & -3.46 & 0.19 \\
\hline Ce-144 & 14.38 & 7.30 & 14.38 & 7.68 & -91.81 \\
\hline Sm-147 & 1.55 & 2.17 & 0.92 & -0.32 & -1.87 \\
\hline Sm-148 & -1.94 & -5.44 & -1.94 & -1.94 & 4.05 \\
\hline Sm-149 & -5.71 & -6.21 & -6.70 & -5.22 & 0.36 \\
\hline Sm-150 & 6.01 & 3.48 & 6.01 & 4.49 & 5.57 \\
\hline Sm-151 & -1.55 & -0.63 & -1.90 & -4.32 & 24.47 \\
\hline Sm-152 & 5.38 & 3.08 & 4.17 & 1.33 & 26.91 \\
\hline Sm-154 & 7.84 & 5.41 & 7.84 & 5.81 & 6.68 \\
\hline Eu-153 & -6.89 & -8.04 & -7.20 & -6.79 & -6.86 \\
\hline Eu-154 & 5.42 & 3.18 & 6.17 & 6.17 & 6.03 \\
\hline Eu-155 & 7.90 & 6.75 & 9.04 & 9.33 & -24.57 \\
\hline Gd-154 & 42.67 & 42.27 & 44.06 & 44.46 & 41.84 \\
\hline Gd-155 & 21.05 & 19.87 & 22.23 & 22.82 & -8.99 \\
\hline Gd-156 & 6.60 & 1.43 & 6.78 & 3.09 & 9.34 \\
\hline Gd-158 & 33.19 & 29.02 & 21.74 & 19.66 & 27.76 \\
\hline Gd-160 & 11.25 & 8.20 & 11.38 & 8.71 & -6.23 \\
\hline Ru-106 & -22.92 & -27.83 & -23.20 & -28.11 & -89.37 \\
\hline La-139 & 2.81 & 1.16 & 2.81 & 1.71 & 5.88 \\
\hline Tc-99 & 2.35 & 0.81 & 2.01 & 0.64 & 7.09 \\
\hline
\end{tabular}

\footnotetext{
${ }^{1}$ From now on also called the LINK[[MONTEBURNS 2.0] ${ }^{*}$ system.
} 
Table 4

Comparison (C/E-1)*100\% for WZR0058 samples at 1101 days from discharge with and without all the capabilities.

\begin{tabular}{|c|c|c|c|c|c|c|c|c|}
\hline \multirow[t]{2}{*}{ Isos.id } & \multicolumn{2}{|l|}{ E58-88 } & \multicolumn{2}{|l|}{ E58-148 } & \multicolumn{2}{|l|}{ E58-260 } & \multicolumn{2}{|l|}{ E58-700 } \\
\hline & {$[42.5]^{n, i}$} & [42.5] & {$[54.8]^{n, i}$} & [54.8] & {$[64.7]^{n, i}$} & [64.7] & {$[77]^{n, i}$} & [77] \\
\hline U-234 & 8.04 & 7.32 & -5.85 & -3.70 & 25.41 & 30.54 & 19.22 & 25.09 \\
\hline U-235 & 0.58 & 1.64 & -10.08 & -3.65 & 5.88 & 24.33 & 0.80 & 13.56 \\
\hline U-236 & 7.39 & 6.77 & -1.02 & -2.50 & 3.40 & 1.71 & 9.49 & 6.34 \\
\hline Pu-238 & -8.10 & -10.60 & 9.13 & 2.27 & -10.47 & -19.29 & -11.95 & -15.74 \\
\hline Pu-239 & -3.50 & -5.13 & 0.05 & 0.71 & -0.71 & -1.06 & -3.08 & -3.70 \\
\hline Pu-240 & 2.72 & 0.59 & 3.29 & 4.32 & 2.40 & -4.84 & 1.75 & 3.82 \\
\hline Pu-241 & -1.92 & -3.57 & 7.58 & 2.38 & -0.52 & -3.77 & 0.30 & -6.43 \\
\hline Pu-242 & 0.64 & -3.03 & 12.18 & 3.25 & -0.05 & -8.78 & -3.56 & -6.22 \\
\hline $\mathrm{Np}-237$ & -7.37 & -6.58 & -18.86 & -18.82 & -9.26 & -13.02 & -8.29 & -3.43 \\
\hline Am-241 & 21.50 & 21.50 & 29.82 & 30.21 & 18.26 & 21.10 & 21.47 & 18.26 \\
\hline Am-243 & 36.24 & 30.47 & 13.77 & 4.10 & 17.50 & -1.71 & 27.11 & 4.07 \\
\hline $\mathrm{Cm}-244$ & 76.86 & 76.86 & 72.56 & 65.66 & 59.63 & 26.16 & 86.79 & 46.51 \\
\hline $\mathrm{Cm}-246$ & 46.36 & 11.92 & 141.64 & 71.80 & 68.10 & -15.88 & 85.04 & 27.35 \\
\hline Nd-142 & 28.49 & -67.19 & 32.51 & -66.70 & 20.45 & -71.87 & 16.49 & -27.41 \\
\hline Nd-143 & -3.10 & -4.64 & -0.25 & -2.13 & -0.81 & -3.44 & -0.93 & -3.64 \\
\hline Nd-145 & -2.81 & -3.38 & -0.95 & -3.37 & -3.16 & -8.12 & -4.36 & -9.05 \\
\hline Nd-146 & -0.12 & -1.97 & 1.98 & -2.30 & 0.45 & -7.15 & -0.25 & -5.26 \\
\hline Nd-148 & -1.30 & -2.35 & 7.09 & 3.95 & 0.73 & -5.50 & -2.83 & -7.56 \\
\hline Nd-150 & -3.38 & -4.83 & 5.05 & 1.29 & -2.70 & -9.45 & 4.15 & -1.07 \\
\hline Cs-133 & -1.47 & -2.51 & 1.89 & -1.23 & -7.25 & -12.32 & 4.63 & 1.01 \\
\hline Cs-134 & -20.98 & -23.88 & -9.33 & -17.55 & -9.97 & -24.22 & -2.60 & -15.25 \\
\hline Cs-135 & -14.31 & -16.49 & -18.76 & -21.50 & -24.22 & -28.30 & -6.85 & -14.65 \\
\hline Cs-137 & -9.72 & -10.94 & -4.19 & -7.09 & -5.44 & -11.86 & -2.98 & -8.56 \\
\hline Ce-140 & -2.71 & -4.38 & 1.21 & -2.34 & -4.28 & -10.71 & -2.05 & -7.08 \\
\hline Ce-142 & -2.44 & -3.46 & -2.20 & -5.03 & -3.22 & -8.80 & -3.21 & -7.39 \\
\hline Ce- 144 & 14.38 & 7.68 & 20.65 & 6.58 & 18.23 & 0.46 & 21.94 & 5.18 \\
\hline Sm-147 & 1.55 & -0.32 & 5.27 & 4.48 & 12.78 & 13.01 & 10.64 & 8.34 \\
\hline Sm-148 & -1.94 & -1.94 & 2.10 & -5.83 & 5.99 & -5.19 & 6.75 & 0.59 \\
\hline Sm-149 & -5.71 & -5.22 & -3.46 & -12.23 & -1.15 & -4.31 & 9.48 & -3.61 \\
\hline $\mathrm{Sm}-150$ & 6.01 & 4.49 & 3.91 & 1.84 & 5.93 & -0.33 & 3.45 & -1.02 \\
\hline Sm-151 & -1.55 & -4.32 & 4.09 & 5.18 & 3.82 & 3.01 & -2.40 & -9.02 \\
\hline Sm-152 & 5.38 & 1.33 & 6.18 & -1.87 & 0.05 & 2.96 & 0.72 & -4.38 \\
\hline Sm-154 & 7.84 & 5.81 & 19.71 & 14.74 & 25.37 & 13.92 & 15.59 & 7.42 \\
\hline Eu-153 & -6.89 & -6.79 & -6.56 & -8.32 & -8.62 & -15.55 & -7.47 & -8.98 \\
\hline Eu-154 & 5.42 & 6.17 & 7.97 & 7.78 & 15.31 & 3.14 & 33.53 & 28.62 \\
\hline Eu-155 & 7.90 & 9.33 & -0.43 & -1.52 & 10.22 & -4.15 & 17.85 & 12.81 \\
\hline Gd-154 & 42.67 & 44.46 & 21.20 & 25.64 & 49.48 & 39.91 & 30.64 & 28.52 \\
\hline Gd-155 & 21.05 & 22.82 & 8.11 & 7.18 & 27.78 & 11.90 & 14.82 & 10.32 \\
\hline Gd-156 & 6.60 & 3.09 & 2.60 & -3.17 & 4.04 & -12.89 & -1.20 & $-\mathbf{1 1 . 5 6}$ \\
\hline Gd-158 & 33.19 & 19.66 & 34.82 & 11.46 & 44.52 & 3.93 & 46.66 & 2.47 \\
\hline Gd-160 & 11.25 & 8.71 & 29.45 & 23.39 & 31.56 & 18.36 & 31.35 & 21.32 \\
\hline $\mathrm{Ru}-106$ & -22.92 & -28.11 & -12.20 & -22.17 & -11.51 & -26.97 & -5.42 & -19.48 \\
\hline La-139 & 2.81 & 1.71 & - & - & 9.33 & 2.66 & 4.23 & -0.61 \\
\hline Tc-99 & 2.35 & 0.64 & - & - & - & - & - & - \\
\hline
\end{tabular}

Table 5

Groups of improved nuclides for $42.5 \mathrm{GWd} / \mathrm{MTU}$ case.

\begin{tabular}{|c|c|c|}
\hline Impact & $\left\|\Delta_{n, i} \mid / /\right\| \Delta \|$ & Nuclides \\
\hline $\begin{array}{l}42.5 \mathrm{GWd} / \mathrm{MTU} \\
\text { Unchanged }\end{array}$ & {$[1.1,0.9]$} & $\begin{array}{l}\text { U-234, U-236, Am-241, Cm-244, Sm-148, } \\
\text { Sm-149, Eu-153, Gd-154, Gd-155 }\end{array}$ \\
\hline Improved & $\begin{array}{l}{[0.9,0.7]} \\
{[0.7,0.5]} \\
{[0.5,0.0]}\end{array}$ & $\begin{array}{l}\text { Pu-238, Pu-240, Nd-145, Cs-134, Cs-135, } \\
\text { Cs-137, Ce-142, Eu-154, Eu-155, Ru-106 } \\
\text { Pu-239, Pu-241, Nd-143, Nd-148, Nd-150, } \\
\text { Cs-133, Ce-140 } \\
\text { U-235, Pu-242, Nd-142, Nd-146, Sm-151 }\end{array}$ \\
\hline
\end{tabular}

Table 6

Groups of improved nuclides 54.8 GWd/MTU case.

\begin{tabular}{lll}
\hline \multicolumn{1}{l}{ Impact } & $\left\|A_{n, i}\right\| /\|\boldsymbol{A}\|$ & Nuclides \\
\hline $\begin{array}{l}\text { 54.8 GWd/MTU } \\
\text { Unchanged }\end{array}$ & {$[1.1,0.9]$} & Np-237, Am-241, Eu-154, La-139 \\
Improved & {$[0.9,0.7]$} & Pu-240, Nd-146, Cs-135, Sm-151, Eu-153, Gd- \\
& & 154 \\
& {$[0.7,0.5]$} & Cs-134, Cs-137, Ce-140, Ru-106 \\
& {$[0.5,0.0]$} & U-236, Pu-239, Nd-142, Nd-143, Nd-145, Ce- \\
& & 142, Sm-148, Sm-149, Eu-155 \\
\hline
\end{tabular}

separately but they do when are applied at the same time: Pu-238, $\mathrm{Pu}-241$. However, it can be seen that most of them improve mainly because of the application of the normalization method, so we conclude that this capability is the main responsible of the obtained accuracy.

\subsection{Effect of the implemented capabilities on isotopic prediction at increasing burnups}

Since Vandellós-II program is focused on high burnup spent fuel, we apply our methodology to the isotopic prediction calculation in samples of higher burnup, those listed in Table 2 . The samples, extracted from different axial positions, were modeled and executed following the same philosophy than in Section 4.1: for each one, an execution was performed with a complete selection of our capabilities and another one with none of them selected. A comparison between the results of these calculations is shown in Table 4.

As expected, an important improvement in the prediction of U235 has been achieved. The reduction in the deviation from measured values is clear in the lowest burnup but it is especially meaningful for samples E58-260 and E58-700, burnt up to $64.7 \mathrm{GWd} /$ MTU and 77 GWd/MTU respectively. However, U-235 content in 
Table 7

Groups of improved nuclides $64.7 \mathrm{GWd} / \mathrm{MTU}$ case.

\begin{tabular}{|c|c|c|}
\hline Impact & $\left\|\boldsymbol{A}_{n, i}\right\| /\|\Delta\|$ & Nuclides \\
\hline $\begin{array}{l}64.7 \text { GWd/MTU } \\
\text { Unchanged }\end{array}$ & {$[1.1,0.9]$} & $\mathrm{Sm}-147$ \\
\hline Improved & $\begin{array}{l}{[0.9,0.7]} \\
{[0.7,0.5]} \\
{[0.5,0.0]}\end{array}$ & $\begin{array}{l}\text { U-234, Am-241, Cm-244, Sm-148, Eu-153, Cs-135, Sm-151, Np-237 } \\
\text { Pu-238, Pu-239, Cs-133 } \\
\text { U-235, Pu-240, Pu-241, Pu-242, Nd-142, Nd-143, Nd-145,Nd-146, Nd-148, Nd-150, Cs-134, Cs-137, } \\
\text { Ce-140, Ce-142, Sm-149, Sm-152, Gd-156, Ru-106 }\end{array}$ \\
\hline
\end{tabular}

Table 8

Groups of improved nuclides $77 \mathrm{GWd} / \mathrm{MTU}$ case.

\begin{tabular}{|c|c|c|}
\hline Impact & $\left\|\mathcal{A}_{n, i}\right\| \Delta \|$ & Nuclides \\
\hline $\begin{array}{l}77 \mathrm{GWd} / \mathrm{MTU} \\
\text { Unchanged }\end{array}$ & {$[1.1,0.9]$} & Gd-154 \\
\hline Improved & $\begin{array}{l}{[0.9,0.7]} \\
{[0.7,0.5]} \\
{[0.5,0.0]}\end{array}$ & $\begin{array}{l}\text { U-234, Pu-238, Pu-239, Eu-153 } \\
\text { Pu-242, Nd-142 } \\
\text { U-235, Pu-240, Pu-241, Nd-143, Nd-145, Nd-146, Nd-148, Cs-134, Cs-135, Cs-137, Ce-140, Ce-142, Sm-151, Sm-152, Gd-156, Ru-106 }\end{array}$ \\
\hline
\end{tabular}

Table 9

Isotopic concentrations -combined data (in\% g/g U-238). From Ilas and Gauld, 2009.

\begin{tabular}{|c|c|c|c|c|c|c|c|c|}
\hline \multirow{2}{*}{$\begin{array}{l}\text { Sample } \\
\text { Nuclide }\end{array}$} & \multicolumn{2}{|c|}{ E58-88 (42.5 GWd/MTU) } & \multicolumn{2}{|c|}{ E58-148 (54.8 GWd/MTU) } & \multicolumn{2}{|c|}{ E58-260 (64.6 GWd/MTU) } & \multicolumn{2}{|c|}{$\mathrm{E} 58-700(77 \mathrm{GWd} / \mathrm{MTU})$} \\
\hline & Mass \% g/g U238 & Uncert (\%) & Mass \% g/g U238 & Uncert (\%) & Mass $\% \mathrm{~g} / \mathrm{g} \mathrm{U} 238$ & Uncert (\%) & Mass \% g/g U238 & Uncert (\%) \\
\hline U-234 & $2.45 \mathrm{E}-02$ & 17.6 & $2.32 \mathrm{E}-02$ & 14.6 & $1.61 \mathrm{E}-02$ & 40.2 & $1.45 \mathrm{E}-02$ & 16.9 \\
\hline U-235 & $1.33 \mathrm{E}+00$ & 11.2 & $9.21 \mathrm{E}-01$ & 6.9 & $5.25 \mathrm{E}-01$ & 13.6 & 3.19E-01 & 6.3 \\
\hline $\mathrm{U}-236$ & $5.68 \mathrm{E}-01$ & 9.9 & $6.87 \mathrm{E}-01$ & 7.3 & $6.77 \mathrm{E}-01$ & 13.2 & $6.63 \mathrm{E}-01$ & 5.3 \\
\hline Pu-238 & $2.83 \mathrm{E}-02$ & 5.2 & $4.02 \mathrm{E}-02$ & 13.3 & 6.77E-02 & 7.5 & $8.93 \mathrm{E}-02$ & 3 \\
\hline Pu-239 & $6.48 \mathrm{E}-01$ & 3 & $6.42 \mathrm{E}-01$ & 6.9 & $6.60 \mathrm{E}-01$ & 4 & $6.72 \mathrm{E}-01$ & 2.5 \\
\hline Pu-240 & $2.49 \mathrm{E}-01$ & 3.4 & $2.93 \mathrm{E}-01$ & 7 & $3.40 \mathrm{E}-01$ & 5 & $3.74 \mathrm{E}-01$ & 2.8 \\
\hline Pu-241 & 1.39E-01 & 3.9 & $1.60 \mathrm{E}-01$ & 7.2 & $1.87 \mathrm{E}-01$ & 7 & $2.01 \mathrm{E}-01$ & 3 \\
\hline Pu-242 & $5.78 \mathrm{E}-02$ & 4.1 & $9.20 \mathrm{E}-02$ & 7.2 & $1.40 \mathrm{E}-01$ & 7.3 & $1.89 \mathrm{E}-01$ & 3.2 \\
\hline $\mathrm{Np}-237$ & $6.68 \mathrm{E}-02$ & 11.3 & $9.99 \mathrm{E}-02$ & 16 & 1.10E-01 & 11.4 & 1.19E-01 & 8 \\
\hline Am-241 & $2.60 \mathrm{E}-02$ & 7.4 & $2.88 \mathrm{E}-02$ & 6.5 & 3.30E-02 & 6.5 & $3.30 \mathrm{E}-02$ & 4.2 \\
\hline Am-243 & $9.49 \mathrm{E}-03$ & 8.1 & $2.45 \mathrm{E}-02$ & 12 & $3.73 \mathrm{E}-02$ & 7.4 & $5.57 \mathrm{E}-02$ & 6.7 \\
\hline $\mathrm{Cm}-244$ & $1.91 \mathrm{E}-03$ & 14.1 & $5.96 \mathrm{E}-03$ & 20 & $1.32 \mathrm{E}-02$ & 14.2 & $2.30 \mathrm{E}-02$ & 10 \\
\hline $\mathrm{Cm}-246$ & $1.85 \mathrm{E}-05$ & 21.2 & $6.23 \mathrm{E}-05$ & 30 & $2.42 \mathrm{E}-04$ & 21.2 & $5.75 \mathrm{E}-04$ & 15.1 \\
\hline Nd-142 & $2.31 \mathrm{E}-03$ & 4.4 & $3.83 \mathrm{E}-03$ & 14.4 & $6.14 \mathrm{E}-03$ & 6.9 & $9.51 \mathrm{E}-03$ & 3.2 \\
\hline Nd-143 & $1.15 \mathrm{E}-01$ & 3.6 & $1.26 \mathrm{E}-01$ & 5.2 & $1.34 \mathrm{E}-01$ & 4.4 & $1.40 \mathrm{E}-01$ & 2.6 \\
\hline Nd-145 & $9.29 \mathrm{E}-02$ & 4.3 & $1.12 \mathrm{E}-01$ & 5.1 & $1.29 \mathrm{E}-01$ & 4.4 & $1.47 \mathrm{E}-01$ & 2.8 \\
\hline Nd-146 & $9.55 \mathrm{E}-02$ & 2.9 & $1.26 \mathrm{E}-01$ & 4.4 & $1.57 \mathrm{E}-01$ & 2.9 & $1.96 \mathrm{E}-01$ & 2.2 \\
\hline Nd-148 & $5.05 \mathrm{E}-02$ & 3.9 & $6.60 \mathrm{E}-02$ & 5.3 & 7.67E-02 & 4.4 & $9.58 \mathrm{E}-02$ & 2.6 \\
\hline Nd-150 & $2.43 \mathrm{E}-02$ & 3.7 & $3.00 \mathrm{E}-02$ & 5.7 & $3.93 \mathrm{E}-02$ & 6.1 & $4.51 \mathrm{E}-02$ & 3.2 \\
\hline Cs-133 & $1.53 \mathrm{E}-01$ & 11.3 & $1.83 \mathrm{E}-01$ & 16 & $2.28 \mathrm{E}-01$ & 16 & $2.25 \mathrm{E}-01$ & 8 \\
\hline Cs-134 & $1.68 \mathrm{E}-02$ & 11.8 & $2.44 \mathrm{E}-02$ & 8.2 & $3.41 \mathrm{E}-02$ & 6.9 & $4.48 \mathrm{E}-02$ & 4.6 \\
\hline Cs-135 & 8.91E-02 & 16 & $1.04 \mathrm{E}-01$ & 16 & 1.18E-01 & 16 & $1.05 \mathrm{E}-01$ & 9.2 \\
\hline Cs-137 & $1.71 \mathrm{E}-01$ & 7.9 & $2.10 \mathrm{E}-01$ & 6.8 & $2.54 \mathrm{E}-01$ & 6.2 & 2.99E-01 & 4.4 \\
\hline Ce-140 & $1.70 \mathrm{E}-01$ & 3 & $2.12 \mathrm{E}-01$ & 3.6 & $2.66 \mathrm{E}-01$ & 3.5 & 3.12E-01 & 2.3 \\
\hline Ce-142 & $1.57 \mathrm{E}-01$ & 2.8 & $2.01 \mathrm{E}-01$ & 3 & $2.41 \mathrm{E}-01$ & 6.2 & $2.85 \mathrm{E}-01$ & 2.2 \\
\hline Ce-144 & $2.04 \mathrm{E}-02$ & 14.5 & $2.45 \mathrm{E}-02$ & 13 & $2.87 \mathrm{E}-02$ & 13.1 & $3.26 \mathrm{E}-02$ & 9.2 \\
\hline Sm-147 & $2.84 \mathrm{E}-02$ & 5.4 & $2.97 \mathrm{E}-02$ & 4.8 & 2.82E-02 & 9.1 & $2.88 \mathrm{E}-02$ & 4.3 \\
\hline Sm-148 & $2.02 \mathrm{E}-02$ & 4.4 & $3.00 \mathrm{E}-02$ & 4.7 & $3.83 \mathrm{E}-02$ & 5 & $5.05 \mathrm{E}-02$ & 3.1 \\
\hline $\mathrm{Sm}-149$ & $3.58 \mathrm{E}-04$ & 11.4 & 3.95E-04 & 13.2 & $3.85 \mathrm{E}-04$ & 13.6 & $3.87 \mathrm{E}-04$ & 8.4 \\
\hline $\mathrm{Sm}-150$ & 3.50E-02 & 4.8 & 4.72E-02 & 4.6 & 5.50E-02 & 5 & $6.66 \mathrm{E}-02$ & 3 \\
\hline Sm-151 & $1.53 \mathrm{E}-03$ & 6.8 & $1.55 \mathrm{E}-03$ & 7.3 & $1.65 \mathrm{E}-03$ & 6.6 & $1.95 \mathrm{E}-03$ & 3.6 \\
\hline Sm-152 & $1.31 \mathrm{E}-02$ & 3 & $1.55 \mathrm{E}-02$ & 4.5 & $1.71 \mathrm{E}-02$ & 4.3 & $1.92 \mathrm{E}-02$ & 2.9 \\
\hline Sm-154 & $4.36 \mathrm{E}-03$ & 6.5 & $5.63 \mathrm{E}-03$ & 5.4 & $6.87 \mathrm{E}-03$ & 8.7 & $9.65 \mathrm{E}-03$ & 3.5 \\
\hline Eu-153 & $1.69 \mathrm{E}-02$ & 5.8 & $2.24 \mathrm{E}-02$ & 5 & $2.73 \mathrm{E}-02$ & 8.8 & $3.08 \mathrm{E}-02$ & 3.6 \\
\hline Eu-154 & $2.36 \mathrm{E}-03$ & 11.8 & $3.38 \mathrm{E}-03$ & 6.2 & $3.98 \mathrm{E}-03$ & 13.1 & 4.12E-03 & 5.5 \\
\hline Eu-155 & $6.16 \mathrm{E}-04$ & 6.8 & 9.79E-04 & 9.5 & $1.18 \mathrm{E}-03$ & 9.6 & $1.30 \mathrm{E}-03$ & 5.3 \\
\hline Gd-154 & $8.87 \mathrm{E}-04$ & 3.3 & $1.54 \mathrm{E}-03$ & 9.2 & $1.59 \mathrm{E}-03$ & 5.7 & $2.21 \mathrm{E}-03$ & 3.8 \\
\hline Gd-155 & 2.99E-04 & 16.9 & $4.87 \mathrm{E}-04$ & 16.5 & $5.48 \mathrm{E}-04$ & 9.5 & 7.15E-04 & 4.4 \\
\hline Gd-156 & $9.58 \mathrm{E}-03$ & 2.8 & $1.92 \mathrm{E}-02$ & 9.1 & $2.93 \mathrm{E}-02$ & 3.8 & $4.74 \mathrm{E}-02$ & 2.7 \\
\hline Gd-158 & $1.70 \mathrm{E}-03$ & 3.7 & $3.01 \mathrm{E}-03$ & 10.3 & 4.31E-03 & 4.3 & $6.97 \mathrm{E}-03$ & 2.9 \\
\hline Gd-160 & 1.39E-04 & 13 & $1.84 \mathrm{E}-04$ & 31.9 & $2.40 \mathrm{E}-04$ & 19.9 & $3.24 \mathrm{E}-04$ & 4.4 \\
\hline $\mathrm{Ru}-106$ & $1.49 \mathrm{E}-02$ & 10.4 & $1.99 \mathrm{E}-02$ & 8.6 & $2.60 \mathrm{E}-02$ & 7.6 & 3.22E-02 & 5.5 \\
\hline La-139 & $1.61 \mathrm{E}-01$ & 16 & & & $2.86 \mathrm{E}-01$ & 16 & 2.59E-01 & 16 \\
\hline Tc-99 & $1.03 \mathrm{E}-01$ & 16 & $1.63 \mathrm{E}-01$ & 16 & & & & \\
\hline
\end{tabular}


E58-148 is worse predicted when activating the developed capabilities. Pu-239, though, is better calculated in the whole range of burnups, even for E58-148. In fact, it is noticeable that nuclear fuel and major actinides are the most affected by the application of our methodology, leading in general to better results, but in sample E58-148, the number of actinides improved is lower and there is an inverse estimation of the uranium and some plutonium isotopes in comparison with the rest of the calculations, that is: uranium is overestimated in all cases and underestimated in E58-148. Regarding to fission products, neodymium, caesium and cerium are generally more accurately estimated, as well as other isotopes at different burnups from which it is not possible to infer some kind of rule of thumb. It is important to note that our capabilities affect negatively to the prediction of americium and curium. Nevertheless, the results are poor without them, what suggests a wrong treatment of the reactions implied in their formation and decay by the original code or a poor quality in the nuclear data library used for them.

The data, as presented in Table 4, may seem to the reader obscure at a first glance, but it encloses a trend in the prediction that can be appreciated if the results are processed under a criterion defined to identify the nuclear isotopes improved. Firstly, we define the $C / E-1$ ( $C$ means calculated values; $E$ means experimental values) as

$(C / E-1) \%=\Delta$

for those values obtained from a simulation that does not consider any of our improvements. On the other hand, $\Delta_{n, i}$ are the deviations $(C / E-1) \%$ from simulations including the new capabilities previously described. We consider that the accuracy of the prediction remains unchanged if $\Delta_{n, i}$ satisfies

$0.9\|\Delta\| \leqslant\left\|\Delta_{n, i}\right\| \leqslant 1.1\|\Delta\|$

and that our calculations improve the results provided by the original code if it is satisfied the relation

$\left\|\Delta_{n, i}\right\| \leqslant 0.9\|\Delta\|$

the improvement factor, $\left\|\Delta_{n, i}\right\| /\|\Delta\|$, helps us to establish groups of improvement within which the nuclides can be categorized. Tables 5-8 collect, for each burnup value, the nuclides for which our system provides deviations both compatible and better than those obtained from the original MONTEBURNS 2.0 code. We conclude that the number of nuclides predicted with an improved accuracy increases with burnup as well as the magnitude of this improvement, affecting especially to main actinides and fission products. As can be seen, $64.7 \mathrm{GWd} / \mathrm{MTU}$ and $77 \mathrm{GWd} / \mathrm{MTU}$ concentrate a higher number of nuclides in the best ranges of improvement than the lower burnup cases. Since we can attribute almost entirely this increasing in the accuracy to the new power normalization factor implemented, as demonstrated for the $42.5 \mathrm{GWd} / \mathrm{MTU}$ case in Section 4.1 , it can be said that the activation of the normalization option is desirable when predicting isotopic contents of high burnup samples. Once demonstrated the impact on the calculations of our implementations, the question is whether they are compatible with experimental data or not.

\subsection{Averaged compatibility with experimental measurements}

The experimental determination of nuclide concentrations (\%g isotope $\} / g$ U-238) in spent nuclear fuel entails a chain of delicate processes leading to uncertainties that, as in our case of study, can range from values like $3-30 \%$, depending on the isotope and the technique used, though in most of the cases the experimental uncertainties are below $10 \%$ (Ilas and Gauld, 2009). It has been demonstrated that the deviations we obtain (by normalizing the power to the sample of interest and managing the isotopic infor- mation with LINK) are lower than those obtained from calculations performed with the original MONTEBURNS 2.0. Now we wonder whether all these deviations are on average compatible with experimental data. To answer this question, for each isotope and burnup, it is calculated the value

$\frac{\|(C-E)\|}{\sigma}=N$

where $\sigma$ is the experimental uncertainty and $N$ indicates whether the calculated value, $C$, is within the error margins of the experimental value, $E$, depending on its value: $N \leqslant 1$ indicates they are compatible. Once calculated, this value is averaged isotope by isotope in burnup for the results obtained from SCALE 6.0, MONTEBURNS 2.0 and the system LINK/[MONTEBURNS 2.0 $]^{*}$ and, then, compared.

Table 9 (Tables 3 and 4 in llas and Gauld, 2009) shows the experimental values (isotopic concentrations taken as experimental values after a process of data treatment. A reading of the reference is highly recommended) and their uncertainty for the nuclides considered. Table 10 contains a general overview of the quality of our results. As shown, on average, for major actinides the prediction is compatible with experimental data ( $N$ averaged

Table 10

Averaged compatibility calculated with experimental values.

\begin{tabular}{|c|c|c|c|}
\hline Isotope & SCALE 6.0 & LINK/MB2 & MB2 \\
\hline U-234 & 0.5 & 0.7 & 0.7 \\
\hline U-235 & 0.8 & 0.5 & 1.2 \\
\hline U-236 & 0.6 & 0.7 & 0.6 \\
\hline Pu-238 & 0.7 & 1.9 & 2.5 \\
\hline Pu-239 & 0.7 & 0.6 & 0.9 \\
\hline Pu-240 & 2.0 & 0.6 & 0.8 \\
\hline Pu-241 & 0.3 & 0.4 & 1.0 \\
\hline Pu-242 & 1.8 & 0.7 & 1.1 \\
\hline Np-237 & 0.4 & 0.9 & 0.8 \\
\hline Am-241 & 4.1 & 3.9 & 3.8 \\
\hline Am-243 & 4.1 & 3.0 & 1.2 \\
\hline $\mathrm{Cm}-244$ & 7.1 & 5.5 & 3.8 \\
\hline $\mathrm{Cm}-246$ & 1.2 & 3.9 & 1.4 \\
\hline Nd-142 & 4.2 & 4.2 & 9.7 \\
\hline Nd-143 & 0.3 & 0.4 & 1.0 \\
\hline Nd-145 & 0.3 & 0.8 & 1.6 \\
\hline Nd-146 & 0.8 & 0.2 & 1.5 \\
\hline Nd-148 & 0.3 & 0.7 & 1.4 \\
\hline $\mathrm{Nd}-150$ & 0.9 & 0.9 & 0.9 \\
\hline Cs-133 & 0.6 & 0.3 & 0.3 \\
\hline Cs-134 & 2.1 & 1.2 & 2.7 \\
\hline Cs-135 & 0.8 & 1.1 & 1.4 \\
\hline Cs-137 & 0.3 & 0.9 & 1.6 \\
\hline Ce-140 & 0.7 & 0.8 & 2.1 \\
\hline Ce-142 & 0.4 & 0.9 & 1.9 \\
\hline Ce-144 & 1.9 & 1.6 & 0.4 \\
\hline Sm-147 & 0.3 & 1.3 & 1.1 \\
\hline Sm-148 & 0.7 & 1.1 & 0.7 \\
\hline Sm-149 & 1.0 & 0.5 & 0.5 \\
\hline Sm-150 & 1.2 & 1.1 & 0.4 \\
\hline Sm-151 & 5.9 & 0.5 & 1.1 \\
\hline Sm-152 & 9.0 & 0.9 & 0.8 \\
\hline Sm-154 & 2.7 & 3.1 & 1.8 \\
\hline Eu-153 & 0.7 & 1.4 & 1.8 \\
\hline Eu-154 & 2.9 & 2.3 & 1.8 \\
\hline Eu-155 & 3.1 & 1.4 & 1.1 \\
\hline Gd-154 & 8.5 & 8.0 & 7.7 \\
\hline Gd-155 & 1.3 & 2.0 & 1.3 \\
\hline Gd-156 & 1.6 & 1.0 & 2.3 \\
\hline Gd-158 & 8.3 & 9.7 & 2.0 \\
\hline Gd-160 & 1.2 & 2.6 & 1.8 \\
\hline Ru-106 & 0.8 & 1.5 & 3.1 \\
\hline La-139 & 0.4 & 0.3 & 0.1 \\
\hline Tc-99 & 0.1 & 0.0 & 0.0 \\
\hline
\end{tabular}


is lower than 1) and more accurate than the prediction provided by the original MONTEBURNS 2.0. Descending the table, we find that a poor estimation of americium and cerium is common to the three codes used. Regarding to neodymium, cerium and caesium families, they are generally in good agreement with experimental data and the prediction is improved by the application of our methodologies. Results for samarium are close to the experimental error margins and, finally, regarding to europium and gadolinium isotopes it can be seen a poor prediction that is common for the three codes.

4.4. Inconsistencies in the predictions of sample E58-148, burned up to $54.8 \mathrm{GWd} / \mathrm{MTU}$

The process followed to analyze our calculations shows inconsistencies in the prediction for the sample E58-148 isotopic content that must be mentioned. They can be noticed in Table 4 , where we present the $(C / E-1) \%$ results that MONTEBURNS 2.0 and LINK/[MONTEBURNS 2.0 $]^{*}$ lead to. This table makes clear a trend in the effect of the capabilities tested that is not observed entirely by sample E58-148, especially for some major actinides and burnup indicators like ${ }^{148} \mathrm{Nd}$. Figs. 4 and 5 illustrate this phenomenon.

Both figures exemplify the information provided throughout the previous sections about the influence of the capabilities developed. It can be noted the good agreement with experimental data at each burnup and the improvement they suppose when compared with the MONTEBURNS 2.0 results. We want to highlight with Figs. 4 and 5 that these facts are in contradiction with the calculations for the $54.8 \mathrm{GWd} / \mathrm{MTU}$ burnup case, for which final U235 content is underestimated and, consistently, ${ }^{148} \mathrm{Nd}$ content is overestimated beyond the experimental error margins. This phenomenon may suggest problems in the measurement of E58-148 isotopic content or burnup estimation that must be underlined because it could be behind the behavior of the results for the 54.8 GWd/MTU case.

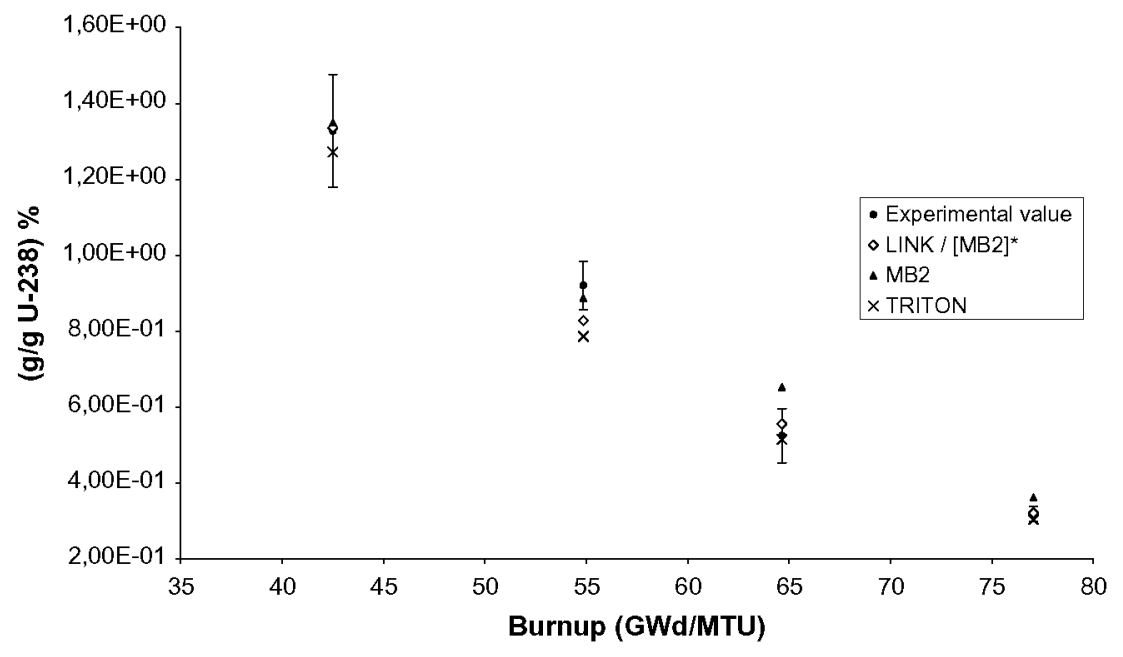

Fig. 4. U-235 calculated values from TRITON, LINK/[MB2 $]^{*}$ and MB2 simulations against experimental values.

Nd-148

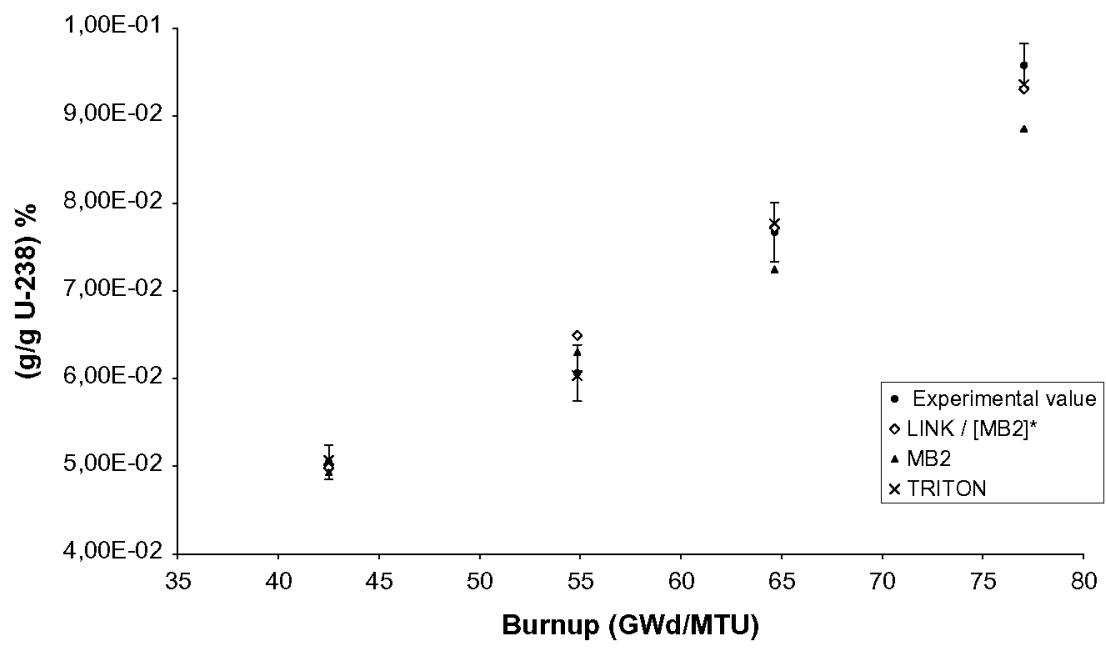

Fig. 5. Nd-148 calculated values from TRITON, LINK/[MB2] $]^{*}$ and MB2 simulations against experimental values. 


\section{Conclusions and future work}

In order to reproduce the measured isotopic content of samples irradiated in a changing position within the reactor core up to increasing values of burnup, several capabilities have been developed. First, and external module, LINK, to perform the executions and manage the complete information related to the isotopic content of the materials of interest. Without it, it is not possible to reproduce the changing surrounding geometry throughout the irradiation history. Second, a new version of MONTEBURNS 2.0 has been developed. Its main feature is the possibility of selecting a specific material as basis of normalization and, this way, it is possible to reproduce the experimental burnup values more accurately.

In this work, it has been proved their importance and we have determined the huge impact of the normalization method on the prediction of major actinides and, more specifically, of U-235 at high burnups. The tools here introduced lead to predictions that improve with burnup and that are generally within the experimental error margins. However, there are actinides and fission products whose prediction seems to be problematic no matter the code used. Americium, curium and gadolinium are good examples. These weaknesses can indicate nuclear data needs or computational lacks in the treatment of the phenomenology in which these nuclides are involved. Another important feature discovered is the debatable agreement of the isotopic content calculation for E58148 sample, fact that aims to a review both of the calculations and the experimental measurements.

\section{Aknowledgments}

We thank the Spanish Nuclear Safety Council (CSN, Consejo de Seguridad Nuclear) for providing us with all the required informa- tion related to our case of study and sponsoring this work in the framework of the agreement P090531725 on Burnup Credit Criticality Safety. We thank specially Consuelo Alejano and J.M. Conde, who made easy the communication with Germina Ilas and lan $C$. Gauld, of the Oak Ridge National Laboratory, authors of the report Analysis of Experimental Data for High Burnup PWR Spent Fuel Isotopic Validation-Vandellós II Reactor. Finally, the authors would like to thank Germina Ilas and Ian C. Gauld for allowing us to use part of their Vandellos II reactor cycles 7-11 inspiring modelizations and results as reference for the present paper, as well as for their patient assistance and guidance.

\section{References}

Chabert, C., Santamarina, A., 2000, Qualification of the APOLLO2 Assembly Code using PWR-UO2 Isotopic Assays. The importance of irradiation history and thermo-mechanics on fuel inventory prediction. In: International Conference on the Physics of Reactors, PHYSOR2000, Pittsburg, USA, May 7-11.

Chadwick, M.B., et al. 2006, ENDF/B-VII.0 next generation evaluated nuclear data library for nuclear science and technology. Special issue on evaluated nuclear data file ENDF/B-VII.0 nuclear data sheets, 107(12), pp. 2931-3059.

DeHart, Mark D., 2009. TRITON: a two-dimensional transport and depletion module for characterization of spent nuclear fuel, ORNLTM-2005/39 Version 6 vol. I. Sect.T1.

Gauld, I. et al. 2010. Spent nuclear fuel assay data for isotopic validation. OECD/NEA Report (2010) WPNCS-EGADSNF (Expert Group on Assay Data on Spent Nuclear Fuel).

Ilas, G., Gauld, I.C., 2009. Analysis of experimental data for high burnup pwr spent fuel isotopic validation - Vandellos II reactor, NUREG/CR-7013 (ORNL/TM2009/321), U.S. Nuclear Regulatory Commission Office of Nuclear Regulatory Research.

Poston, D.I., Trellue, H.R., 1999. User's Manual, Version 2.0 for MONTEBURNS Version 1.0, LAUR - 99-4999.

$\mathrm{X}-5$ Monte Carlo Team, 2003. MCNP - A general monte carlo N-particle transport code, Version 5 - Los Alamos National Laboratory.

Zwicky, H.U., Low, J., Granfors, M., Alejano, C., Conde, J.M., Casado, C., Sabater, J., Lloret, M., Quecedo, M., Gago, J.A., 2010. Nuclide analysis in high burnup fuel samples irradiated in Vandellos 2. J. Nucl. Mater 402 (1), 60-73. 